\title{
RESSIGNIFICAÇÃO DO MOVIMENTO DA CRIANÇA NA EDUCAÇÃO INFANTIL
}

\author{
Adilse Xavier de Campos Paula ${ }^{1}$ \\ Andréa Cristina Teixeira da Silva ${ }^{2}$ \\ Andreia Menegueti ${ }^{3}$ \\ Elaine Maria da Silva ${ }^{4}$ \\ Elisabete Alves Guimarães ${ }^{5}$ \\ Gercina Fabiana Santana Barros 6 \\ Luana Xavier Gonçalves de Paula ${ }^{7}$ \\ Maria Barbara da Cunha ${ }^{8}$
}

RESUMO: $\mathrm{Na}$ educação infantil, as atividades lúdicas agregam novas vivências e conhecimentos às crianças por meio da produção de significados e ressignificados nas brincadeiras e nos jogos. Os movimentos são articulados no processo de ensinoaprendizagem, produzindo conhecimentos e vivências por meio da geração de significados e ressignificados. O objetivo deste estudo é discutir as potencialidades da psicomotricidade aplicada na ressignificação do movimento da criança na educação infantil, com a apresentação de uma intervenção prática. Este estudo se qualifica como uma pesquisa bibliográfica. $\mathrm{O}$ desenvolvimento deste estudo consiste na compreensão dos movimentos das crianças, para a produção de estratégias de ensino que possibilitem a aprendizagem significativa na educação infantil. A Psicomotricidade estimulou análises e interpretações

\footnotetext{
I Pós-graduado em Educação Infantil com Ênfase em Educação Especial pela Faculdade de Educação Tangará da Serra. Licenciado em Pedagogia pela Universidade Luterana do Brasil. E-mail: adilsecampos@gmail.com

${ }^{2}$ Graduada em Pedagogia - Licenciatura Plena nas Séries Iniciais - Universidade Federal de Mato Grosso (UFMT). Pós-graduada em Avaliação Psicológica - Instituto de Pós-Graduação e Graduação (IPOG). Pósgraduada em Neuropsicologia - Instituto de Pós-Graduação e Graduação (IPOG). E-mail: andrea.psi2013@gmai.com

${ }^{3}$ Especialista em Educação Física pela Universidade Cândido Mendes - Rio de Janeiro. Graduada em Educação Física Licenciatura pela Universidade Cuiabá - UNIC. Professora efetiva da rede pública municipal de Cuiabá-MT.E-mail: andreiamenegueti978@gmail.com

${ }^{4}$ Graduada em Pedagogia pela FIAVEC (faculdades Integradas de Várzea Grande). Pós-graduação em Docência do Ensino Superior pela UNIASSELVI (Centro Universitário Leonardo da Vinci) - 2019. E-mail: educaela@gmail.com

${ }^{5}$ Graduação Licenciatura Plena em Matemática - UFMT. Pós-graduação: Percepção e Investigação: Uma proposta lúdica na Educação Infantil e Anos Iniciais. Ajes (Instituto Superior da Educação do Vale do Juruena - ISE).E-mail: Elisabete.alvesguimaraes@gmail.com

${ }^{6}$ Graduada em Licenciatura Plena em Pedagogia pela UNIC. Pós-graduada em Educação Infantil e Alfabetização pelo ICEC. E-mail: barrosfabiana2ı2@gmail.com

${ }^{7}$ Licenciatura em Pedagogia - UNOPAR. Pós-graduada em psicopedagogia - UNIASSELVI. E-mail: depailaluana765@gmail.com

${ }^{8}$ Graduada em Pedagogia pela Faculdade Varzeagrandense de Ciências Humanas. Pós-graduada em Planejamento Educacional pela Universidade Salgado de Oliveira - UNIVERSO. E-mail: mariabarbaracunha@gmail.com
} 
que proporcionou uma ressignificação do movimento, contemplando a relação entre a mente e o corpo.

Palavras-chave: Psicomotricidade. Educação Infantil. Atividades Lúdicas. Movimento na Criança.

ABSTRACT: In early childhood education, playful activities add new experiences and knowledge to children through the production of meanings and resignifications in games and games. The movements are articulated in the teaching-learning process, producing knowledge and experiences through the generation of meanings and re-meanings. The aim of this study is to discuss the potential of psychomotricity applied to the redefinition of the child's movement in early childhood education, with the presentation of a practical intervention. This study qualifies as bibliographic research. The development of this study consists of understanding the movements of children, to produce teaching strategies that enable meaningful learning in early childhood education. Psychomotricity stimulated analyzes and interpretations that provided a redefinition of the movement, contemplating the relationship between mind and body.

Keywords: Psychomotricity. Child education. Playful Activities. Movement in the Child.

\section{INTRODUÇÃO}

$\mathrm{Na}$ educação infantil, as atividades lúdicas agregam novas vivências e conhecimentos às crianças por meio da produção de significados e ressignificados nas brincadeiras e nos jogos. Estas atividades lúdicas se desenvolvem como estratégias de ensino na educação infantil, demandando planejamento alinhado com os objetivos definidos para o processo de ensino-aprendizagem, visando o desenvolvimento global dos alunos. A ludicidade não se desprende do processo do processo de ensino-aprendizagem, pois dialoga com as habilidades e competências das crianças.

As crianças demandam estímulos dos familiares e dos professores, para se tornarem ativas no processo de ensino-aprendizagem. Os movimentos são articulados no processo de ensino-aprendizagem, produzindo conhecimentos e vivências por meio da geração de significados e ressignificados. Desta maneira, apresenta-se a questão problema: Qual é a importância da psicomotricidade na ressignificação do movimento da criança na educação infantil?

O objetivo deste estudo é discutir as potencialidades da psicomotricidade aplicada na ressignificação do movimento da criança na educação infantil, com a apresentação de uma intervenção prática. Os objetivos específicos são os seguintes: contextualizar a educação infantil; compreender a psicomotricidade na educação infantil; e refletir sobre a ressignificação do movimento da criança na educação infantil.

O desenvolvimento deste estudo consiste na compreensão dos movimentos das crianças, para a produção de estratégias de ensino que possibilitem a aprendizagem significativa na educação infantil. Essa discussão possibilita levantar bases para compreender o desenvolvimento global das crianças no processo de ensino-aprendizagem. A aprendizagem não se restringe na aquisição de conhecimentos pelas crianças, mas envolve também a realização de vivências agregadoras ao desenvolvimento delas na educação infantil. 
Este estudo se qualifica como uma pesquisa bibliográfica, proveniente de abordagens levantadas em artigos científicos, livros, monografias, dissertações de Mestrado e teses de Doutorado. Inicialmente, contextualizou-se o desenvolvimento da aprendizagem na educação infantil e seus aspectos. Sequencialmente, desenvolveu-se uma compreensão sobre a aplicação do conhecimento da psicomotricidade na educação infantil. Finalmente, refletiu-se sobre a ressignificação do movimento nas estratégias de ensino da educação infantil.

\section{EDUCAÇÃO INFANTIL}

A educação infantil é uma etapa da educação da educação básica, que não se resume na realização de brincadeiras e jogos, mas envolve um aprendizado significado por meio destas atividades lúdicas. $\mathrm{O}$ processo de ensino-aprendizagem possui objetivos definidos em conformidade com a linguagem e faixa etária das crianças. O conhecimento pedagógico embasa o desenvolvimento do planejamento das estratégias de ensino e dos recursos didáticos aplicados na educação infantil.

Campos et al (20II) abordam que as últimas décadas do século XX evidenciou uma evolução importante na educação infantil no Brasil, principalmente na expansão da quantidade de matrículas, no quadro legal e no sistema institucional. Os referidos autores enfatizam que os novos marcos legais foram instituídos a partir da Constituição Federal de 1988, reforçando a legitimação dos processos de desenvolvimento da educação infantil. A educação infantil possui demanda por respostas para a sociedade, para promover bases para o aluno ser encaminhado ao ensino fundamental.

Loro (2015) observa que a modernidade oportunizou a introdução de novos modelos e costumes, agregadores na convivência das crianças, principalmente no ambiente escolar, pois os seus pais necessitam trabalhar fora da residência. Campos et al (20II) salientam que a responsabilidade sobre a educação infantil, atribuída aos governos municipais, apressou as tendências de mudanças que precisavam ser impulsionadas e exigidas dos sistemas educacionais. Este contexto legal e institucional possibilitou que a educação infantil se consolidasse como a etapa inicial da educação básica, constituindo uma condição importante no desenvolvimento de políticas públicas educacionais voltadas na sua manutenção.

Fonseca, Colares e Costa (2019) identificam que a criança se constitui como um todo integrado com um todo integrado com uma dinâmica intensa, detentora de uma dependência do adulto nas rotinas de cuidado, vulnerável e demandante de uma atenção privilegiada aos componentes socioemocionais do seu desenvolvimento. De acordo com Oliveira-Formosinho e Formosinho (200I), a educação infantil envolve diversos contextos trabalhados pelos professores pedagogos: contextos pedagógicos, envolve uma intencionalidade educativa definida; e, contexto de custódias, enfoque na guarda segura e nos cuidados das crianças quando os pais trabalham.

Estes contextos evidenciam a complexidade que envolve a educação infantil, principalmente na abordagem de um processo de ensino-aprendizagem que contemple a ludicidade e o desenvolvimento global das crianças. Fonseca, Colares e Costa (2019) ressaltam que esta diversidade de contextos influencia nas condições de trabalho do professor na autonomia profissional, nos processos de trabalho e no estilo de interação com as crianças. Além de estar contemplada no processo de ensino-aprendizagem, estes contextos devem considerados na estruturação da educação infantil. 
A estruturação da educação infantil é fundamental para a formatação de uma plataforma para a construção da aprendizagem das crianças na educação infantil brasileira, sendo fomentada por políticas públicas educacionais específicas. Agostinho (2010) aborda que a promoção da participação e inclusão das crianças na produção de espaços sociais se condiciona ao atendimento delas, na condição de atores sociais, habilitadas ao papel ativo nos processos destes espaços. De acordo com esta autora, as crianças são e devem ser compreendidas como ativas na construção de suas vidas, as vidas dos seus entornos e das sociedades em que se encontram inseridas.

Loro (2015) salienta que a criança é visualizada como um indivíduo que participa e interage socialmente, e a infância como uma fase de brincadeiras, um momento de aprendizado do brincar e da socialização. A condição ativa das crianças no processo de ensino-aprendizagem deve ser efetivada nas concepções aplicadas no planejamento do processo de ensino-aprendizagem, pois o discurso não é suficiente por si, para promover mudanças agregadoras na educação infantil.

A percepção de cidadania ativa da criança se desenvolve contrariando a concepção de homogeneização delas, que atende a dinâmica capitalista vigentes nos sistemas econômico e social do país. Agostinho (2010) observa que a homogeneização privilegia determinadas crianças ou determinados grupos de crianças, em detrimento e silenciamento de outras crianças. Loro (2015) compreende que a condição ativa das crianças demanda que os pais e educadores sejam impulsionados na reflexão sobre as mudanças decorrentes na sociedade, considerando a influências destas a educação dos alunos na educação infantil.

Fonseca, Colares e Costa (2019) enfatizam que a melhoria da educação infantil demanda o comprometimento com a qualidade da formação do seu corpo docente, pois esta contribui para a promoção de práticas educativas. Os referidos autores destacam que estas práticas educativas oportunizam a aquisição de elementos pelas crianças, para participarem ativamente da sociedade. Neste contexto, a psicomotricidade evidencia conhecimentos que contribuem no desenvolvimento de estratégias de ensino para se trabalhar com o movimento e com a mente das crianças no processo de ensino-aprendizagem.

\section{PSICOMOTRICIDADE NA EDUCAÇÃO INFANTIL}

A Psicomotricidade proporciona uma abordagem agregadora na compreensão do desenvolvimento das crianças no processo de ensino-aprendizagem que envolve a educação infantil. Negreiros, Sousa e Moura (2018) abordam que a Psicomotricidade dialoga com as áreas da Psicologia, Sociologia, Biologia, Psicanálise, Educação Física, entre outras, com o objetivo de estudar os movimentos e o desenvolvimento psicomotor do indivíduo. Cunha (2016) ressalta que o termo Psicomotricidade se desenvolveu por meio das influências científicas de diversas áreas do conhecimento, possibilitando que práticas e teorias se desenvolvessem na busca de compreender e trabalhar o corpo.

Negreiros, Sousa e Moura (2018) salientam que os conhecimentos da psicomotricidade se instalaram e desenvolverem no Brasil, durante o século $X X$, fundamentando-se na escola francesa. Os referidos autores complementam que a Sociedade Brasileira de Psicomotricidade foi fundada nos anos de 1980, e a partir deste momento se desenvolveram vários congressos pelo país, que contribuíram para a disseminação dos conhecimentos da psicomotricidade na academia e na sociedade.

Santos e Costa (2015) relatam que as atividades motora e mental passaram a serem visualizadas como interrelacionadas, por meio dos seus componentes: o socioafetivo e o cognitivo. As referidas autoras complementam que a Psicomotricidade contribui 
expressivamente para a formação do esquema corporal, uma condição facilitadora da orientação espacial.

Neste contexto, desenvolvem-se um trabalho pedagógico na educação infantil que contempla a relação entre a mente e o corpo das crianças, por meio de atividades lúdicas de aprendizagem. Oliveira (202I) visualiza que a Psicomotricidade desloca a problemática cartesiana e reformula as relações entre alma e corpo, postulando que o homem é o seu corpo. O deslocamento da problemática cartesiana proporciona uma condição ativa da criança em seu movimento e, consequentemente, em sua aprendizagem.

Zirondi e Leite (2018) visualizam que a Psicomotricidade promove uma relação entre o comportamento humano e a aprendizagem, abrangendo além dos estímulos e respostas, identificando uma sequência de ações em uma dimensão espaço-temporal intencional. As referidas autoras complementam que a Psicomotricidade envolve toda a aprendizagem do indivíduo, apresentando-se indispensável ao desenvolvimento da criança na aquisição dos conceitos demandados na sua condição de sujeito. Essa condição não significa que a aprendizagem da criança é compreendida somente pelos conhecimentos difundidos na educação infantil pela Psicomotricidade.

Oliveira (2021) compreende a Psicomotricidade como um campo transdisciplinar que aborda e investiga as relações e as influências recíprocas e sistêmicas decorrentes entre o psiquismo e a motricidade. De acordo com esta autora, a Psicomotricidade se embasa em uma visão global humano, observando a integração de funções cognitivas, socioemocionais, simbólicas, psicolinguísticas e motoras, proporcionando a capacidade de ser e agir num contexto psicossocial.

Cunha (2016) destaca que a Psicomotricidade abrange todo um conjunto de ações que podem ser desempenhadas pelo indivíduo em uma concepção integradora entre o psiquismo e a motricidade. O referido autor observa que a Psicomotricidade visualiza um desenvolvimento global, com enfoque nos componentes afetivos, motores e cognitivos, possibilitando que o indivíduo se conscientize do seu corpo através do movimento.

Rossi (2012) aborda que a educação psicomotora surgiu a partir dos conhecimentos apresentados pela Psicomotricidade, com o objetivo de ajudar a criança se concretizar em uma imagem do corpo operatório. A referida autora define que a educação psicomotora assumi as seguintes supostas funções: estimuladora, (re) educadora e terapêutica. A educação psicomotora proporciona embasamento para as práticas pedagógicas, que contemplam os conhecimentos da Psicomotricidade.

Fernandes, Gutierres Filho e Rezende (2018) enfatizam que a dimensão motora é indissociável do pensamento que expressa a intenção de cada movimento e das emoções do indivíduo. Os referidos autores complementam que as manifestações conscientes e inconscientes do indivíduo estão concentradas em um paradigma de transposição, que envolvem o agir e reagir, e o interno e o externo. Potel (2oı) observa uma associação que envolve o movimento corporal e as expressões imaginárias-simbólicas, que promovem significados ao corpo a partir do relacionamento dialético com os outros e com os objetos. Portanto, um corpo do indivíduo promove relações e contribui para a construção de significados no contexto do indivíduo.

Monteiro (2015) indica que a psicomotricidade possui uma enorme relação com o processo de aprendizagem, pois o movimento influencia a maturação do sistema nervoso da criança e ainda promove apoio na aquisição do conhecimento referente ao mundo do seu entorno, utilizando-se das percepções e sensações do corpo. Negreiros, Sousa e Moura (2018) enfatizam que o desenvolvimento do Esquema Corporal, Lateralidade, Estruturação Espacial, Orientação Temporal e pré-escrita são importantes na aprendizagem, pois 
apresentando um problema em um destes elementos prejudicará o desempenho do indivíduo.

Jesus, Dantas e Bezerra (2017) consideram que o ambiente escolar é o espaço onde a criança exerce a cidadania, entrando em contato com a diversidade cultural apresentada no contexto social. Os referidos autores visualizam que a diversidade é agregadora na formação de sujeitos críticos, criativos, autônomos e respeitosos capazes de agir no seu meio e transformar. Nas aplicações da Psicomotricidade, a diversidade se apresenta um elemento de trabalho no desenvolvimento das atividades lúdicas com as crianças da educação infantil.

Santos (2019) visualizam que o contexto lúdico é essencial para a socialização das crianças, pois eles aprendem de forma mais eficaz por meio de jogos e brincadeiras. De acordo com este autor, a Psicomotricidade pode ser trabalhada por meio de jogos, brincadeiras, canções e de outras atividades lúdicas. Jesus, Dantas e Bezerra (2017) salientam que as atividades lúdicas devem ser trabalhadas em conformidade com a faixa etária e com a necessidade e limitação de cada criança, com o objetivo de contribuição ao desenvolvimento cognitivo e afetivo dela, e ainda possibilitando quela compreenda as suas limitações e capacidades.

Considerada esta abordagem da Psicomotricidade, as atividades lúdicas possibilitam a ressignificação do movimento, passando pela compreensão da relação do corpo com a mente da criança. O desenvolvimento das atividades lúdicas possibilita as crianças explorarem diversas vivências e conhecimentos por meio do movimento integrado ao seu pensamento. A diversidade cultural encontra-se presente na ressignificação do movimento, um processo desenvolvido por meio das atividades lúdicas aplicadas no processo de ensino-aprendizagem da educação infantil.

\section{RESSIGNIFICAÇÃO DO MOVIMENTO DA CRIANÇA}

O movimento é um componente bastante presente na infância, sendo contributivo para o desenvolvimento da criança. Richter (2006) aborda a definição fisiológica de que o movimento é o resultado da atividade muscular e das estruturas cerebrais, sendo estas responsáveis pela sua organização. A referida autora indica que os seres humanos e quase todos os animais se utilizam dos músculos para a realização do movimento. O movimento vai além de sua definição fisiológica, pois ele possui significado e ressignificado, e ainda apoia a produção de significado e ressignificado de outros elementos.

Almeida e Almeida (2020) enfatizam que o homem se movimenta de forma global e integrada ao mundo e aos seus sentidos, em decorrência do seu movimento ser feito junto com uma percepção de si mesmo e do mundo em que vive, possibilitando o indivíduo interagir completamente com os outros seres e o seu meio. As referidas autoras compreendem que o movimento do corpo no mundo está condicionado à intenção do sujeito que o realiza, consequentemente, os sentidos e os conhecimentos ampliam as concepções que envolvem os movimentos e a interação com o meio, a motricidade. Estas intenções do indivíduo estão relacionadas à sua construção, que passa pelos seus movimentos.

Rios (2019) define que o desenvolvimento motor contempla a aquisição de um amplo conjunto de habilidades motoras, que proporciona para a criança um amplo domínio do seu corpo em diferentes situações, realizar a locomoção de diversas formas pelo ambiente e manipular objetos e instrumentos diversos. De acordo com esta autora, essas 
habilidades básicas são demandadas para a realização de rotinas do cotidiano, como são utilizadas em propósitos lúdicos da infância.

O desenvolvimento motor encontra-se alinhado com o ato de brincar, envolvido por diversas manifestações lúdicas da criança. Antonio, Viotto Filho e Nunes (2018) ressaltam que a atividade de brincar oportuniza a criança de se apropriar dos objetos culturais desenvolvidos no processo histórico do homem, se constituindo fundamental na educação escolar. Os referidos autores abordam que o desenvolvimento de habilidades e capacidades humanas é estimulado pelo brincar, alinhando-se com o processo de aprendizagem e desenvolvimento das crianças da educação infantil.

O desenvolvimento cultural da criança passa pelo movimento, no seu acesso e compreensão sobre os objetos e situações. Rios (2019) destaca que a cultura demanda o domínio de várias habilidades pelas crianças, desde os primeiros anos de suas vidas. De acordo com esta autora, os padrões de comportamento humano se configuram classificado em três domínios: cognitivo (operações mentais), afetivo-social (sentimentos e emoções) e motor (movimentos). Estes domínios possibilitam que o desenvolvimento motor do indivíduo produza significados e ressignificados, contribuindo para o desenvolvimento global do indivíduo.

Almeida e Almeida (2020) compreendem que os movimentos humanos se congregam com as ações e percepções de si e do mundo, promovendo a motricidade humana, consiste em um processo de uma ressignificação do movimento e sua interligação com o ser, em uma concepção menos dual e menos fragmentada. As referidas autoras complementam que se desenvolvem mudanças para a sua humanização, em qualquer dimensão de movimento corporal. Rios (2019) enfatiza que o aprender pelo movimento será fundamental na estruturação desse sujeito que se forma: a criança.

Baltazar, Rabelo e Souza (2014) enfatizam que a aprendizagem é fundamental no desenvolvimento da criança, envolvendo os fatores neurológicos, socioculturais e psicoemocionais. Os referidos autores abordam que o desenvolvimento intelectual da criança e suas capacidades e de construção e reconstrução encontram-se relacionadas ao domínio e emprego do seu corpo, pois a motricidade antecede a psicomotricidade.

Negreiros, Sousa e Moura (2018) visualizam a importância dos estímulos psicomotores na criança, desde o seu nascimento até aproximadamente aos oitos anos de idade. Os referidos autores justificam que nesta fase de desenvolvimento da criança é o momento em que ocorrem as principais dificuldades de aprendizagem, que são prejudiciais na fala, na escrita e na leitura. Os conhecimentos da psicomotricidade auxiliam o professor trabalhar estratégias que confrontem estas dificuldades de aprendizagem na educação infantil.

Os professores são atores fundamentais no desenvolvimento da psicomotricidade na educação infantil, por meio da aplicação destes conhecimentos nas práticas pedagógicas componentes do processo de ensino-aprendizagem da educação infantil. Cunha (2016) alerta pela necessidade destes profissionais buscarem cada vez mais aprofundamento nos conhecimentos da psicomotricidade na educação infantil, para atendimento das reais necessidades da criança, inclusive promovendo a ampliação das atividades corporais diversificadas nas práticas pedagógicas. $O$ referido autor complementa que o trabalho psicomotor é composto pelos seguintes fatores: esquema corporal, estruturação espacial e orientação temporal com enfoque no conhecimento sobre a criança; o conhecimento do meio em que está inserida e as relações desenvolvidas com o meio são fundamentais no contexto escolar. 
O trabalho psicomotor deve envolver um real significado para a criança e a sua participação nas ações de intervenção, contribuindo para uma construção de concepções próprias em relação aos componentes de movimento, de espaço e de movimento. Negreiros, Sousa e Moura (2018) compreendem que a educação psicomotora desenvolvida na educação infantil deve se fundamentar em um enfoque preventivo e abrangente de suas várias fases de desenvolvimento. Os referidos autores observam que as atividades lúdicas psicomotoras são agregadoras ao desenvolvimento social, psicológico e da aprendizagem escolar.

Rossi (2012) salienta que a psicomotricidade infantil se desenvolve por meio de estímulos aos movimentos da criança, com enfoque nas seguintes metas: motivar a capacidade sensitiva por meio das sensações e relações entre o corpo e o exterior; promover a capacidade perceptiva por meio da identificação dos movimentos e da resposta do corpo; organizar a capacidade dos movimentos desenvolvidos; estimular a descoberta e a expressão das suas capacidades, por meio da emoção e da criatividade; ampliar e valorizar a identidade própria e a autoestima nos grupos sociais; criar segurança e a capacidade expressão, se valorizando e respeitando aos outros. Estas metas contribuem para definir o trabalho psicomotor a ser desenvolvido pelo professor junto aos alunos da educação infantil.

O movimento não é somente uma ação, mais um fator fundamental no processo de construção do ser e, consequentemente, do seu desenvolvimento global. O movimento não está dissociado da mente, conforme se identifica nas atividades lúdicas, como as brincadeiras que se desenvolvem na educação infantil.

\section{CONSIDERAÇÕES FINAIS}

A Educação Infantil é uma etapa inicial da educação básica, abrangendo crianças até os seis anos da idade. As crianças são integradas e possuem uma dinâmica intensa, mas são dependentes dos adultos, vulneráveis e demandam cuidados e atenção. $\mathrm{Na}$ infância, as crianças vivenciam diversos contextos, produzindo amplos vivências, experiências e conhecimentos. Estes contextos influenciam a estruturação da educação infantil, inclusive no trabalho dos professores. As crianças produzem espaços sociais, quando as oportunizam de participação e de inclusão, pois elas devem ser visualizadas como agentes ativas na construção de suas vidas, as vidas dos seus entornos e das sociedades em que se encontram inseridas. A qualidade do processo educacional na educação infantil passa pela abordagem da diversidade, pois a homogeneização privilegia crianças de determinados grupos sociais.

A Psicomotricidade proporciona mudanças nas concepções referentes às relações entre mente e corpo, aplicando-se ao movimento. A aprendizagem está relacionada ao comportamento humano, por meio de estímulos, respostas e ações em uma dimensão espaço-temporal intencional. A Psicomotricidade está presente no desenvolvimento da criança na aquisição dos conceitos demandados na sua condição de sujeito. A transdisciplinaridade da Psicomotricidade se desenvolve entre o psiquismo e a motricidade, embasando-se numa visão global do homem, visando as suas diversas integrações. As atividades lúdicas são enriquecidas pelos conhecimentos da Psicomotricidade. Neste contexto de ludicidade, a diversidade é agregadora na formação de sujeitos críticos, criativos, autônomos e respeitosos capazes de agir no seu meio e transformar.

O movimento não se restringe a sua definição fisiológica, pois se alinha ao desenvolvimento global da criança. Os conhecimentos da Psicomotricidade possibilitaram 
a compreensão de uma relação positiva entre o movimento e a aprendizagem da criança. A intenção da criança condiciona o seu movimento, com os sentidos e os conhecimentos ampliando as suas concepções em um contexto de movimentos e interações. As habilidades motoras possibilitam que a criança domine o seu corpo, contribuindo para o seu desenvolvimento motor, pois estas habilidades são demandadas no seu cotidiano e aplicadas nas atividades lúdicas. O comportamento humano não se restringe ao domínio motor, contemplando os domínios cognitivo e afetivo-social, todos se integrando para o desenvolvimento global. O aprender pelo movimento é uma das bases de construção da criança como ser social e cidadão.

Desta maneira, conclui-se que a Psicomotricidade estimulou análises e interpretações que proporcionou uma ressignificação do movimento, contemplando a relação entre a mente e o corpo. O movimento se agrega aos outros domínios do corpo, contribuindo para a criança produzir significados e ressignificados de objetos e situações. Neste contexto, as crianças desenvolvem as suas vivências e experiências, sendo agentes de construção de seus conhecimentos, e se constituindo um ser crítico.

Considerada esta abordagem, sugere-se o desenvolvimento de um estudo sobre a relação da aplicação da Psicomotricidade na construção de atividades lúdicas na educação infantil. Este tema sugerido possibilita o aprofundamento da abordagem deste estudo.

\section{REFERÊNCIAS BIBLIOGRÁFICAS}

AGOSTINHO, Kátia Adair. Formas de participação das crianças na Educação Infantil. 20I0. 348f. Tese (Doutorado em Estudos da Criança), Universidade do Minho, Braga, 2010.

ALMEIDA, Claudia Regina; ALMEIDA, Érica Cristina. A importância do movimento na alfabetização da criança. Revista da Universidade Ibirapuera Jan/jun, n. 19, p. 23-31, 2020. Disponível em: 〈http://www.seer.unib.br/index. php/rev/article/view/223〉. Acesso em I5 de setembro de 202I.

ANTONIO, Larissa Zangarini; VIOTTO FILHO, Irineu Aliprando Tuim; NUNES, Rodrigo Lima. Dos jogos populares à cultura corporal de movimento na educação física: reflexões acerca do desenvolvimento da consciência da criança. Colloquium Humanarum, vol. I5, n. Especial 2, Jul-Dez, 2018, p. 236-242. Disponível em: 〈http://www.unoeste.br/site/enepe/2018/suplementos/area/Humanarum/Educa\% $\%$ 3\%A 7\%C 3\%A30/DOS\%20JOGOS\%20POPULARES\%20\%C3\%80\%20CULTURA\%20CORP ORAL\%20DE\%20MOVIMENTO\%20NA\%2oEDUCA\%C3\%87\% $\mathrm{C}_{3} \% 83 \mathrm{O} \% 20 \mathrm{~F} \% \mathrm{C}_{3} \% 8 \mathrm{D}$ SICA\%20REFLEX\%C3\%95ES\%20ACERCA\%20DO\%20DESENVOLVIMENTO\%2oD A\%20CONSCI\%C3\%8ANCIA\%20DA\%20CRIAN\%C3\%87A.pdf $>$. Acesso em is de setembro de 202I.

BALTAZAR, Beatriz Fernanda Ferreira; RABELLO, Elaine Cristina; DE SOUZA, Gleicione Aparecida Dias Bagne. A Psicomotricidade no Processo de Aprendizagem. Revista da Universidade Vale do Rio Verde, v. I2, n. I, p. 979-987, 2016. Disponível em: <http://periodicos.unincor.br/index.php/revistaunincor/article/ view/2952>. Acesso em I5 de setembro de 2021. 
CAMPOS, Maria Malta et al. A qualidade da educação infantil: um estudo em seis capitais brasileiras. Cadernos de pesquisa, v. 4I, n. I42, p. 20-54, 20II. Disponível em: $<$ https://www.scielo.br/scielo.php?pid=Soroo-1574201100oıo $\quad$ o03\&script=sci_ arttext\&tlng=pt $>$. Acesso em is de setembro de 202I.

CUNHA, Edivan Carlos da. A psicomotricidade na Educação Infantil: ressignificação de práticas pedagógicas. 2016. 122f. Dissertação (Mestrado em Educação Escolar), Universidade Federal de Rondônia, Porto Velho, 2016.

FERNANDES, Jorge Manuel Gomes de Azevedo; GUTIERRES FILHO, Paulo José Barbosa; REZENDE, Alexandre Luiz Gonçalves de. Psicomotricidade, jogo e corpo-emrelação: contribuições para a intervenção. Cadernos Brasileiros de Terapia Ocupacional, v. 26, n. 3, p. 702-709, 2018. Disponível em: <https://www.scielo.br/ scielo.php?pid=S2526$89102018000300702 \&$ script $=$ sci_arttext $>$. Acesso em I5 de setembro de 2021.

FONSECA, André Dioney; COLARES, Anselmo Alencar; COSTA, Sinara Almeida. Educação infantil: história, formação e desafios. Educação \& Formação, v. 4, n. 3, p. 82-103, 2019. Disponível em: 〈https://revistas.uece.br/index.php/redufor/article/ view/r270〉. Acesso em is de setembro de 2021.

JESUS, Luany Silva; DANTAS, Vanda Maria Campos Salmeron; BEZERRA, Ada Augusta Celestino. Psicomotricidade na educação infantil: um breve estudo sobre sua contribuição no desenvolvimento da aprendizagem. In: Encontro Internacional de Formação de Professores e Fórum Permanente de Inovação Educacional, v. Io, n. I, 2017. Aracaju: UNIT, 2017.

LORO, Aline Rafaela. A importância do brincar na educação infantil. 2015.4If. Trabalho de Conclusão de Curso (Bacharelado em Educação Física), Universidade Regional do Noroeste do Estado do Rio Grande do Sul, Santa Rosa, 2015.

MONTEIRO, Cláudia Sofi a Nunes. A importância da psicomotricidade na Educação Pré-Escolar. 2015.7of. Dissertação (Mestrado em Educação Pré-Escolar). Instituto Superior de Educação e Ciências, Lisboa, 2015.

NEGREIROS, Fauston; SOUSA, Carolina Machado de; MOURA, Francisca Kétsia Lourenço Gomes de. Psicomotricidade e práticas pedagógicas no contexto da Educação Infantil: uma etnografia escolar. Revista Educação e Emancipação, v. II, n. I, p. I30-I5I, 2018. Disponível em: 〈http://www.periodicoseletronicos.ufma.br/ index.php/reducacaoemancipacao/article/view/8910>. Acesso em is de setembro de 202I.

OLIVEIRA, Carolina Maurício. Aspectos relevantes da psicomotricidade na educação infantil. Revista Autênticos, p. 67, v.I, jan. 2021, São Paulo. Disponível em: $\langle$ https://www.revistaautenticos.com.br/gallery/Revista\%2oAutenticos.pdf \#page $=67\rangle$. Acesso em is de setembro de 202I.

OLIVEIRA-FORMOSINHO, João; FORMOSINHO, Júlia. Associação Criança - um contexto de formação em contexto. Braga: Livraria Minho, 2001. 
POTEL, Catherine. Être psychomotricien: um métier du présent, un métier d'avenir. Toulouse: Érès, 2010.

RICHTER, Leonice Matilde. Movimento corporal da criança na educação infantil: expressão, comunicação e interação. 2006. 174f. Dissertação (Mestrado em Educação), Universidade Federal de Uberlândia, Uberlândia, 2006.

RIOS, Mara Rúbia Andrade. Os aspectos motores da criança. Unificada: Revista Multidisciplinar da FAUESP, v. I, n. I, p. 15-34, 2019. Disponível em: 〈http://revista. fauesp.com.br/index.php/Unificada/article/download/4/ro>. Acesso em is de setembro de 202I.

ROSSI, Francieli Santos. Considerações sobre a psicomotricidade na educação infantil. Vozes dos Vales, Diamantina, n. I, p. I-I8, 2012. Disponível em: 〈http:// ufvjm.edu.br/site/revistamultidisciplinar/files/2011/o9/Considera\% $\mathrm{C}_{3} \% \mathrm{~A} 7 \% \mathrm{C}_{3} \% \mathrm{~B}_{5}$ essobre-a-Psicomotricidade-na-Educa $\% \mathrm{C}_{3} \% \mathrm{~A}_{7} \% \mathrm{C}_{3} \% \mathrm{~A}_{30}$-Infantil.pdf $>$. Acesso em is de setembro de 202I.

SANTOS, Alessandra dos; COSTA, Gisele M. Tonin. A psicomotricidade na educação infantil: um enfoque psicopedagógico. Rev de Educação do IDEAU, v. Io, n. 22, p. I-I2, 2015. Disponível em: 〈https://www.getulio.ideau.com.br/wp-content/files_mf/ 39aa38262do2c2edb9c379bife67796e278_I.pdf>. Acesso em is de setembro de 2021.

SANTOS, Leonardo Sucupira Marra Ribeiro dos. Análise da importância da 1068 psicomotricidade na educação infantil. 2019. 28f. Trabalho de Conclusão de Curso (Licenciatura em Educação Física), Centro Universitário de Brasília, Brasília, 2019.

ZIRONDI, Ana Paula; LEITE, Sandra Regina Mantovani. A importância da psicomotricidade na educação infantil: algumas contribuições. In: Encontro Internacional de Formação de Professores e Fórum Permanente de Inovação Educacional, v. II, n. I, 2018. Anais...Aracaju: UFSE, 2018. 